\title{
Effect of Treatment with Prostaglandin Synthetase Inhibitors on the Erythrocyte Sodium Transport Abnormality of Bartter's Syndrome
}

\author{
C. H. $\operatorname{COLE}^{(20)}$ AND S. O'REGAN \\ Nephrology Division, Department of Medicine, Royal Victoria Hospital, and Nephrology Service, Hôpital Sainte \\ Justine, Montreal, Quebec, Canada
}

\begin{abstract}
Summary
The basic pathogenetic defect in patients with Bartter's syndrome remains unknown, although the possibility that a defect in membrane ion transport underlies the syndrome has been explored by several investigators. The purpose of the present study was to investigate abnormalities in erythrocyte sodium transport in five patients with Bartter's syndrome and to examine the effect of treatment with prostaglandin synthetase inhibitors on these abnormalities.

In five patients with Bartter's syndrome, the rate of passive sodium leak from the erythrocyte was $1.04 \pm 0.21$ mmoles of sodium per liter of erythrocytes per hr, compared to $0.39 \pm 0.06$ mmoles of sodium per liter of erythrocytes per hr in controls $(P$ $<\mathbf{0 . 0 2 5}$ ). Treatment with prostaglandin synthetase inhibitors had little effect on this erythrocyte sodium transport abnormality. After treatment with either acetylsalicylic acid at a dosage of $\mathbf{5 0}$ $\mathrm{mg} / \mathrm{kg} / \mathrm{day}$ or indomethacin at a dosage of $100 \mathrm{mg} / \mathrm{day}$, the rate of passive sodium leak averaged $0.96 \pm 0.10$ mmoles of sodium per liter of erythrocytes per hr in the patients with Bartter's syndrome. In vitro there was no significant effect of prostaglandin $E_{2}$ on erythrocyte sodium transport, nor did a lowered potassium concentration in vitro reproduce the changes in sodium transport which we had noted in patients with Bartter's syndrome.

We would conclude that one of the basic abnormalities in patients with Bartter's syndrome is a disorder in electrolyte transport at the level of the cell membrane. Prostaglandin synthetase inhibitors have been demonstrated to reverse many of the secondary manifestations of Bartter's syndrome, but they did not seem to affect the membrane transport defect.
\end{abstract}

\section{Speculation}

The most basic defect described to date in patients with Bartter's syndrome may be an abnormality in electrolyte transport at the level of the cell membrane. The abnormality does not appear to be altered by treatment with prostaglandin synthetase inhibitors; perhaps this explains the failure of these agents to totally correct the clinical syndrome.

The basic pathogenetic defect in patients with Bartter's syndrome remains unknown, although the secondary changes that comprise the syndrome have been well described. The possibility that a defect in membrane ion transport underlies this syndrome has been explored by several investigators. Gall et al. (10) in 1971 reported increased active and passive sodium efflux from the erythrocytes of a patient with Bartter's syndrome. One year later, Gardner et al. (11) reported that six of eight patients with Bartter's syndrome showed a decreased rate constant for total sodium efflux from their erythrocytes. More recently, Oliver et al. (15) have reported increased permeability to sodium in the erythrocyte membrane of five siblings with Bartter's syndrome. Abnormalities in membrane transport in tissue other than the erythrocyte have also been described. Delaporte et al. (6) have described abnormalities in muscle electrolytes in six children with Bartter's syndrome, and Gill and Bartter (12) have drawn attention to an abnormality in chloride reabsorption in the ascending limb of the loop of Henle.

Prostaglandin synthetase inhibitors have now been shown to reverse many of the manifestations of Bartter's syndrome $(3,9)$. The purpose of the present study was to investigate abnormalities in erythrocyte sodium transport in five additional patients with Bartter's syndrome and to examine the effect of treatment with prostaglandin synthetase inhibitors on these abnormalities.

\section{MATERIALS AND METHODS}

\section{PATIENT SELECTION}

The diagnosis of Bartter's syndrome was established before this study on clinical and biochemical grounds. The patients were being followed in the outpatient clinics of the Royal Victoria Hospital and Hôpital Sainte Justine.

Patient 1 was a 4l-year-old male who was first told that he had a low serum potassium at the age of 21 . He treated himself with potassium supplements which he took at irregular intervals and a high potassium diet. His only symptoms were periods of severe fatigue after heavy muscular exertion. There was no family history of similar problems. On physical examination, he appeared to be in good health with a blood pressure of $105 / 75$. His serum potassium was $2.2 \mathrm{mM}$. There was no renal salt wasting. After 4 days of a $100 \mathrm{mEq}$ sodium- $100 \mathrm{mEq}$ potassium diet he had marked hyperreninemia $(5.7 \mathrm{ng} / \mathrm{ml} / \mathrm{hr})$ and hyperaldosteronemia $(42.2$ $\mathrm{ng} / \mathrm{dl}$ ). Ambulant renin levels were $28.6 \mathrm{ng} / \mathrm{ml} / \mathrm{hr}$.

Patient 2 was a 4-year-old who presented at the age of $1 \frac{1 / 2}{2}$ months with failure to thrive. On investigation, he was found to have hypokalemia, hypochloremic metabolic alkalosis, hyperreninemia, and hyperaldosteronism. The diagnosis of Bartter's syndrome was confirmed with an open renal biopsy which disclosed typical juxtaglomerular hyperplasia.

Patient 3 was a 23-year-old man who had the diagnosis of Bartter's syndrome established at the age of 6 years by means of a renal biopsy which showed juxtaglomerular apparatus hyperplasia. He displayed mild mental and growth retardation at the time of our studies.

Patient 4 was a 29-year-old woman with a life-long history of hypokalemic alkalosis associated with episodes of muscle weakness. She had mild staturo-ponderal retardation but attained normal height with a postmenarchial growth spurt. At the age of 16 years, the diagnosis of Bartter's syndrome was confirmed on the basis of hyperreninemia, hyperaldosteronemia, and juxtaglomerular hyperplasia on renal biopsy.

Patient 5 was a 19-year-old boy who had presented at numerous institutions for the first 6 years of life with what was diagnosed as 
chronic hypokalemia of unknown etiology. More extensive investigation at the age of 6 years revealed hypokalemia, hypochloremia with alkalosis, hyperreninemia, and a high aldosterone excretion rate. An open renal biopsy showed typical histologic features of Bartter's syndrome. Subsequent to the presently reported studies, he developed aortic incompetence of unknown etiology and has required therapy for cardiac failure.

The initial sodium flux studies were done in patients 1,3 , and 4 before treatment with prostaglandin synthetase inhibitors was started. In two additional patients, prostaglandin synthetase inhibitors were stopped at least 6 days before the study. All patients had a serum potassium between 2 and $3 \mathrm{mM}$ at the time of the erythrocyte sodium efflux studies. The four patients who were studied after treatment with prostaglandin synthetase inhibitors were receiving acetylsalicylic acid at a dosage of $50 \mathrm{mg} / \mathrm{kg} /$ day and/or indomethacin at a dosage of $100 \mathrm{mg} /$ day. The shortest duration of treatment was 11 days.

\section{SODIUM EFFLUX STUDIES}

Fifteen $\mathrm{ml}$ of blood were drawn in a heparinized syringe from both the patient to be studied and a control volunteer. Tight pairing of the patient and control samples was adhered to throughout the experiment. The blood was centrifuged at $12000 \times g$ for $5 \sec$ at $0^{\circ} \mathrm{C}$, and the plasma and buffy coat were removed. The remaining erythrocytes were then washed three times with 10 volumes of cold $280 \mathrm{mM}$ tetramethylammonium chloride. Four $\mathrm{ml}$ of erythrocytes were loaded with ${ }^{22} \mathrm{Na}$ by incubating them for $3 \mathrm{hr}$ at $37^{\circ} \mathrm{C}$ in a flask containing $50 \mu \mathrm{l}$ of $120 \mathrm{mM}$ phosphate buffer ( $\mathrm{pH} 7.4$ ), $0.45 \mathrm{ml}$ of $0.16 \mathrm{M} \mathrm{NaCl}, 10 \mu \mathrm{l}$ of $50 \%$ glucose, and $10 \mu \mathrm{Ci}$ of ${ }^{22} \mathrm{Na}$. After the loading period, $200 \mu \mathrm{l}$ of the erythrocytes were transferred to three pairs of flasks containing a basic flux medium, the basic flux medium plus $10^{-4} \mathrm{M}$ ouabain or the basic flux medium plus $10^{-4} \mathrm{M}$ ouabain and $10^{-3} \mathrm{M}$ ethacrynic acid. The basic flux medium in these experiments consisted of $5 \mathrm{mM} \mathrm{KCl}, 160 \mathrm{mM} \mathrm{NaCl}, 1.2 \mathrm{mM}$ phosphate buffer (pH 7.4), $8 \mathrm{mM}$ glucose, and $10 \%$ isotonic glyclglycine- $\mathrm{Mg} \mathrm{CO}$ buffer (pH 7.4). At 0;20;40; and 60-min intervals, a $5 \mathrm{ml}$ aliquot of the erythrocyte suspension was removed from each flask, the erythrocytes were separated by centrifugation, and the ${ }^{22} \mathrm{Na}$ of the supernate was determined with a Packard auto-gamma spectrometer. The rate constant for ${ }^{22} \mathrm{Na}$ efflux was then determined from the equation

$$
{ }^{0} \mathrm{~K}_{\mathrm{Na}} \mathrm{t}=\ln \frac{1-\mathrm{Na}_{\mathrm{s}} / \mathrm{Na}_{\mathrm{h}}}{1-\text { fractional hemolysis }}
$$

where $\mathrm{Na}_{\mathrm{s}}$ is the activity of supernate in $\mathrm{cpm} / \mathrm{ml}, \mathrm{Na}_{h}$ is the activity of hemolyzed sample in $\mathrm{cpm} / \mathrm{ml}$, and $\mathrm{t}$ is time in hours.

Before the loading period, the sodium content of the erythrocytes was determined on an 1.L. flame photometer by lysing the cells with 50 volumes of $15 \mathrm{mM}$ lithium chloride and relating the sodium content of the hemolysate to the hematocrit of the original suspension. All determinations were performed in duplicate. Additional details of these techniques have been published previously $(4,5)$.

\section{IN VITRO STUDIES ON PROSTAGLANDIN AND KCL}

Studies on the effect of low concentration of $\mathrm{KCl}$ in vitro on erythrocyte sodium transport were performed in an identical manner to that described above, except that the basic flux medium was modified to contain $2.5 \mathrm{mM} \mathrm{KCl}$.

Studies on the effect of prostaglandin on erythrocyte sodium transport were performed with prostaglandin $\mathrm{E}_{2}\left(\mathrm{PGE}_{2}\right)$ supplied by the Upjohn Company of Canada. The PGE 2 was dissolved in ethanol and added to the flux medium, an equal volume of ethanol being added to control flasks.

Preincubation studies were done by adding $\mathrm{PGE}_{2}$ to flasks which contained $100 \mathrm{mg}$ glucose, $0.5 \mathrm{ml} 1 \mathrm{M} \mathrm{NaPO}$ buffer (pH 7.4), 250,000 units Penicillin $\mathrm{G}$, and $50 \mathrm{mg}$ streptomycin sulfate in addition to $10 \mathrm{ml}$ of whole blood. Incubation was carried out for $18 \mathrm{hr}$ at $37^{\circ} \mathrm{C}$ in a shaking water bath, the cells were washed, and sodium flux studies were carried out as described above.

\section{RESULTS}

Erythrocyte sodium transport was studied in five patients with Bartter's syndrome at a time when they were not receiving treatment with prostaglandin synthetase inhibitors. The results are shown in Table 1 . The mean red cell sodium in the five patients with Bartter's syndrome was not significantly different from the mean red cell sodium in five controls. However, three of the five patients had cell sodiums which were more than three standard deviations above the control mean and which were usually high for our laboratory. The mean ouabain-uninhibitable component of sodium efflux was significantly higher $(0.21 \pm 0.03)$ in the patients with Bartter's syndrome than it was in the controls $(0.13$

Table 1. Erythrocyte sodium transport in five patients with Bartter's syndrome

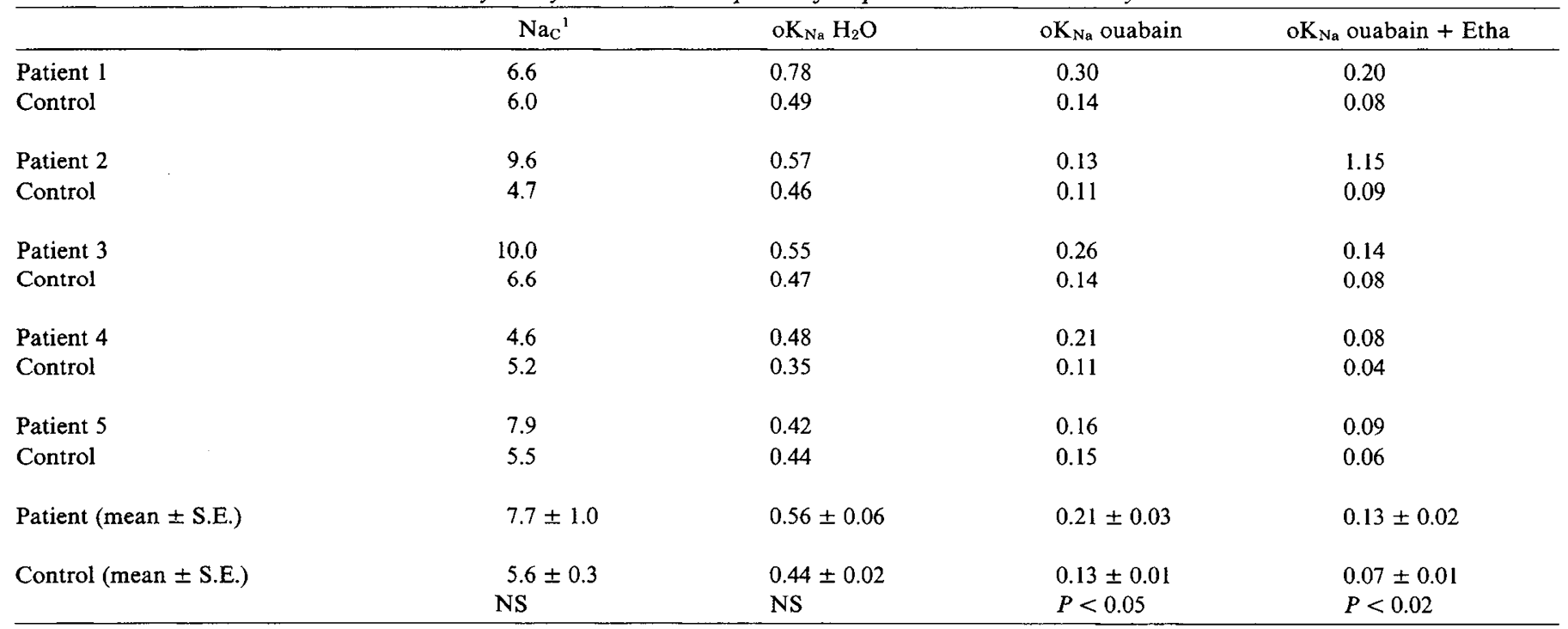

\footnotetext{
${ }^{1} \mathrm{Na}_{\mathrm{C}}$, concentration of sodium within the erythrocytes expressed as $\mathrm{mM} /$ liter of erythrocytes; $\mathrm{oK}_{\mathrm{Na}} \mathrm{H}_{2} \mathrm{O}$, fractional sodium efflux in the absence of any transport inhibitors; $\mathrm{oK}_{\mathrm{Na}}$ ouabain, fractional sodium efflux in the presence of $0.1 \mathrm{mM}$ ouabain; oK $\mathrm{Na}_{\mathrm{Na}}$ oubain + Etha, fractional sodium efflux in the presence of $0.1 \mathrm{mM}$ ouabain and $1 \mathrm{mM}$ ethacrynic acid.
} 


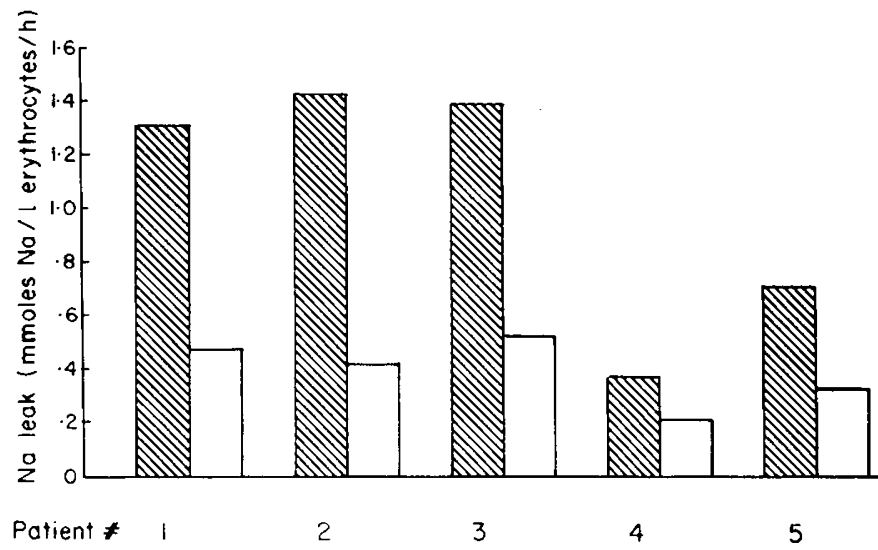

Fig. 1. Passive sodium leak in the erythrocytes of five patients with Bartter's syndrome (cross-hatched bars) and five controls (clear bars).

\pm 0.01 ). That component of sodium efflux which remains after the addition of ouabain plus ethacrynic acid was also significantly higher in the patients with Bartter's syndrome than it was in the controls.

From the data shown in Table 1, it is possible to calculate the rate constants for ouabain-sensitive and ethacrynic acid-sensitive sodium efflux. The rate constant for ouabain-sensitive sodium efflux was $0.35 \pm 0.05$ in the patients with Bartter's syndrome and $0.31 \pm 0.02$ in the controls. The rate constant for ethacrynic acidsensitive sodium efflux was $0.07 \pm 0.02$ in the patients with Bartter's syndrome and $0.06 \pm 0.01$ in the controls.

To obtain an estimate of the total amount of passive sodium efflux from the erythrocytes each hour, sometimes referred to as sodium leak, the rate constant for sodium efflux in the presence of ouabain and ethacrynic acid can be multiplied by the cell sodium. As shown in Figure 1, in the patients with Bartter's syndrome, the rate of passive sodium leak was $1.04 \pm 0.21$ mmoles sodium per liter of erythrocytes per $\mathrm{hr}$ compared to $0.39 \pm 0.06$ mmoles sodium per liter of erythrocytes per hr in the controls $(P<0.025)$.

Increased levels of urinary prostaglandin derivatives have been reported in patients with Bartter's syndrome. Consequently, we next studied the effect of $\mathrm{PGE}_{2}$ in vitro on erythrocyte sodium fluxes in erythrocytes from normal controls. Preliminary studies revealed no effect of $\mathrm{PGE}_{2}$ on erythrocyte sodium transport at concentrations between $0.0002 \mathrm{mg} / 100 \mathrm{ml}$ flux medium and 0.2 $\mathrm{mg} / 100 \mathrm{ml}$ flux medium. The results of preincubating erythrocytes for $18 \mathrm{hr}$ with very large doses of $\mathrm{PGE}_{2}(50 \mathrm{mg} / 100 \mathrm{ml}$ blood $)$ and then performing sodium flux studies are shown in Table 2 . Again there was no statistically significant effect of $\mathrm{PGE}_{2}$ on erythrocyte sodium transport. Four of the Bartter's syndrome patients we had originally studied were treated with prostaglandin synthetase inhibitors, and the erythrocyte transport studies were repeated. The results are shown in Table 3 and Figure 2. The rate constant for non-ouabain-inhibitable sodium efflux from the erythrocyte remained elevated at $0.20 \pm 0.03$ in the patients with Bartter's syndrome compared to $0.13 \pm 0.02$ in the controls. As shown in Figure 2, the rate of passive sodium leak averaged $0.96 \pm 0.10$ in the patients with Bartter's syndrome compared to $0.54 \pm 0.13$ in the controls. It is evident that treatment with prostaglandin synthetase inhibitors had little effect on the erythrocyte sodium transport abnormality.

It has been hypothesized that changes in erythrocyte sodium transport in patients with Bartter's syndrome could result from hypokalemia per se (5). The effect of lowering the potassium concentration of the flux medium to $2.5 \mathrm{mM}$ was studied in five experiments with control erythrocytes. As shown in Table 4, this had no effect on erythrocyte sodium transport, failing to reproduce the changes in sodium transport which we had noted in patients with Bartter's syndrome.

\section{DISCUSSION}

Bartter et al. (2) in 1962, described a syndrome of mental and growth retardation characterized by hypokalemia, hypochloremic alkalosis, and hypersecretion of renin. The basic pathogenesis of this syndrome remains unknown (1). Defects in electrolyte transport at the level of the cell membrane have been described by

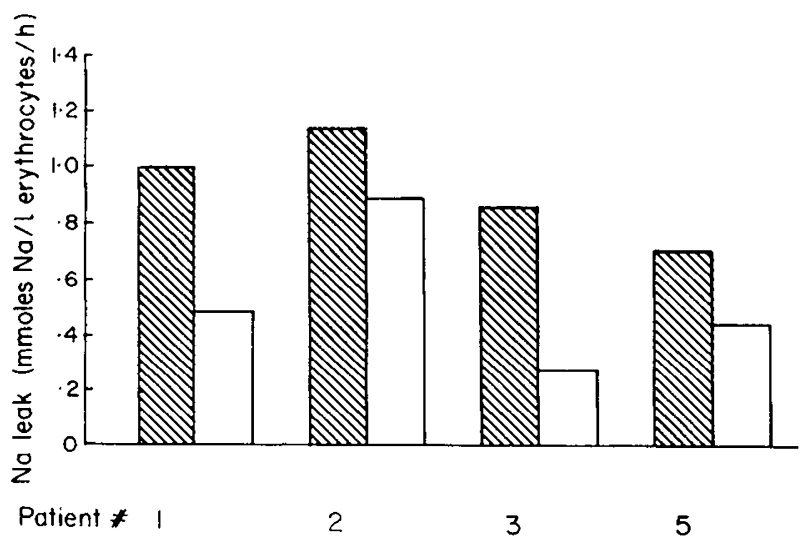

Fig. 2. Passive sodium leak in the erythrocytes of four patients with Bartter's syndrome treated with prostaglandin synthetase inhibitors (crosshatched bars) and four controls (clear bars).

Table 2. Effect of in vitro prostaglandin on erythrocyte sodium transport

\begin{tabular}{|c|c|c|c|c|}
\hline & $\mathrm{Na}_{\mathrm{C}}{ }^{1}$ & $\mathrm{oK}_{\mathrm{Na}} \mathrm{H}_{2} \mathrm{O}$ & oK $\mathrm{K}_{\mathrm{Na}}$ ouabain & $\mathrm{oK}_{\mathrm{Na}}$ ouabain + Etha \\
\hline $\begin{array}{l}\text { Erythrocytes preincubated for } 18 \mathrm{hr} \text { with } 50 \\
\mathrm{mg} \text { of prostaglandin } \mathrm{E}_{2} / 100 \mathrm{ml} \text { blood }(n= \\
\text { 4) }\end{array}$ & $6.8 \pm 1.0^{2}$ & $0.22 \pm 0.04$ & $0.08 \pm 0.02$ & $0.09 \pm 0.01$ \\
\hline \multirow{2}{*}{$\begin{array}{l}\text { Erythrocytes preincubated for } 18 \mathrm{hr} \text { with } \\
\text { vehicle alone }(n=4)\end{array}$} & $6.5 \pm 0.7$ & $0.28 \pm 0.5$ & $0.08 \pm 0.02$ & $0.06 \pm 0.01$ \\
\hline & NS & NS & NS & NS \\
\hline
\end{tabular}

\footnotetext{
${ }^{1}$ Abbreviations, same as in Table 1.

${ }^{2}$ Mean \pm S.E.
}

Table 3. Erythrocyte sodium transport in four patients with Bartter's syndrome treated with prostaglandin synthetase inhibitors

\begin{tabular}{lllll}
\hline & \multicolumn{1}{c}{$\mathrm{NaC}^{1}$} & $\mathrm{oK}_{\mathrm{Na}} \mathrm{H}_{2} \mathrm{O}$ & $\mathrm{oK}_{\mathrm{Na}}$ ouabain & oK \\
\hline Patient & $9.2 \pm 1.7^{2}$ & $0.53 \pm 0.07$ & $0.20 \pm 0.03$ & $0.11 \pm 0.02$ \\
Control & $5.9 \pm 0.4$ & $0.46 \pm 0.03$ & $0.13 \pm 0.02$ & $0.09 \pm 0.02$ \\
& $\mathrm{NS}$ & $\mathrm{NS}$ & $\mathrm{NS}$ & $\mathrm{NS}$ \\
\hline
\end{tabular}

\footnotetext{
'Abbreviations, same as in Table 1.
}

${ }^{2}$ Mean \pm S.E. 
Table 4. Effect of potassium in vitro on erythrocyte sodium transport $(n=5)$

\begin{tabular}{lllll}
\hline & \multicolumn{1}{c}{$\mathrm{NaC}^{1}$} & $\mathrm{oK}_{\mathrm{Na}} \mathrm{H}_{2} \mathrm{O}$ & $\mathrm{oK}_{\mathrm{Na}}$ ouabain & oK $_{\mathrm{Na}}$ Ouabain + Etha \\
\hline $2.5 \mathrm{mM} \mathrm{K}$ & $5.2 \pm 0.02^{2}$ & $0.43 \pm 0.08$ & $0.16 \pm 0.02$ & $0.12 \pm 0.01$ \\
$5 \mathrm{mM} \mathrm{K}$ & $5.2 \pm 0.02$ & $0.45 \pm 0.06$ & $0.15 \pm 0.03$ & $0.09 \pm 0.02$ \\
& $\mathrm{NS}$ & $\mathrm{NS}$ & $\mathrm{NS}$ & $\mathrm{NS}$ \\
\hline
\end{tabular}

${ }^{1}$ Abbreviations, same as in Table 1.

${ }^{2}$ Mean \pm S.E.

several authors $(6,10,11,15)$. The first report of altered erythrocyte sodium transport was by Gall et al. (10) in 1971. They reported a patient with Bartter's syndrome who demonstrated increased active sodium efflux from his erythrocytes, increased passive outward leak of sodium, elevated $\mathrm{NaK}$ ATPase, and an increased concentration of sodium within the erythrocytes. In 1972, Gardner et al. (11) studied erythrocyte sodium transport in eight patients with Bartter's syndrome. Two of the patients had normal sodium transport. The other six patients showed a high erythrocyte sodium concentration and a fractional sodium efflux which was significantly less than normal. Because of methodologic differences, it is difficult to compare these two studies, but it would appear that definite alterations in erythrocyte membrane sodium transport do exist in Bartter's syndrome. In 1978, Oliver et al. (15) studied erythrocyte sodium transport in five siblings with Bartter's syndrome. They found an increase in both passive ouabain-uninhibitable sodium efflux and in sodium influx, indicating increased erythrocyte sodium permeability. The changes in erythrocyte sodium transport in the five patients we have studied most closely resemble those described by Oliver et al. Our patients had a significant increase in the passive ouabain-uninhibitable component of sodium efflux, and three of five patients had an abnormally high cell sodium. When active sodium potassium exchange is maximally inhibited with ouabain, a small component of sodium efflux remains which can be inhibited by ethacrynic acid. Whether this represents a second sodium pump, as suggested by Hoffman, or whether it represents exchange diffusion is not completely clear $(17,14)$. Gardner et al. (11) in their studies on erythrocyte transport in Bartter's syndrome used ethacrynic acid alone to define active sodium efflux, whereas Oliver et al. (15) used ouabain alone. To fully define active transport, both agents were added to our flux studies. The component of sodium efflux which remains when all active transport is inhibited with ouabain and ethacrynic acid was elevated in all five of our patients. The most consistent erythrocyte transport abnormality in patients with Bartter's syndrome would seem to be an increase in erythrocyte sodium permeability. This may lead, in certain patients such as the one described by Gall et al. (10) to a compensatory increase in active sodium efflux. In other patients, such as those described by Gardner et al. (11), the erythrocyte sodium pump may be unable to keep up with the demands and fractional sodium efflux will be decreased.

Oliver et al. (15) have hypothesized that the changes in erythrocyte sodium transport in patients with Bartter's syndrome result from hypokalemia. However, we were unable to demonstrate any effect on erythrocyte sodium fluxes when the potassium concentration in vitro was lowered from 5.0 to $2.5 \mathrm{mM}$.

It has been demonstrated that patients with Bartter's syndrome have an elevation of urinary prostaglandin $E_{2}$ (13). Increased plasma levels of $\mathrm{PGE}_{2}$ could in turn lead to hyperreninemia, increased plasma aldosterone, and low potassium $(8,9,17)$. The reason for increased $\mathrm{PGE}_{2}$ production in Bartter's syndrome has not yet been elucidated $(9,16)$. Gill et al. have shown that patients with Bartter's syndrome have a defect in chloride reabsorption in the thick ascending limb of the loop of Henle, and that this defect is not affected by prostaglandin synthetase inhibitors (12). We were unable to show any effect in vitro of $\mathrm{PGE}_{2}$ on normal red cell erythrocyte transport even when the hormone was added in very high concentration. We also studied erythrocyte sodium transport in patients with Bartter's syndrome who had been treated with prostaglandin synthetase inhibitors. These patients had the same defect in erythrocyte sodium transport which had been noted in patients who were not receiving treatment with prostaglandin synthetase inhibitors.

We would conclude that one of the basic abnormalities in patients with Bartter's syndrome is a disorder in electrolyte transport at the level of the cell membrane. Prostaglandin synthetase inhibitors have been demonstrated to reverse many of the secondary manifestations of Bartter's syndrome, but they do not seem to affect this underlying membrane transport defect.

\section{REFERENCES AND NOTES}

1. Bartter, F. C., Gill, J. R. Jr., and Frolich, J. C.: Barter's syndrome. Ady. Nephrol.. 7: 191 (1977).

2. Bartter, F. C.. Pronove, P., Gill, J. R., Jr., and MacCardle, R. C.: Hyperplasia of the juxtaglomerular complex with hyperaldosteronism and hypokalemic alkalosis. Am. J. Med., 33: 811 (1962).

3. Bowden, R. E., Gill, J. R., Jr., Radfar, N., Taylor, A. A., and Keiser, H. R.: Prostaglandin synthetase inhibitors in Bartter's syndrome. J. Am. Med. Assoc., 239: 117 (1978)

4. Cole, C. H.: Decreased ouabain-sensitive adenosine triphosphatase activity in the erythrocyte membrane of patients with chronic renal disease. Clin. Sci. Mol. Med., 45: 775 (1973).

5. Cole, C. H., Steinberg, R., and Guttmann, R.: Altered erythrocyte sodium efflux following renal transplantation. Nephron, 20: 248 (1978).

6. Delaporte, C., Stulzaft, J., Loirot, C., and Broyer, M.: Muscle electrolytes and fluid compartments in six children with Bartter's syndrome. Clin. Sci. Mol. Med., 54: 223 (1978)

7. Dunn, M. J.: Ouabain uninhibited sodium transport in human erythrocytes. J. Clin. Invest., 52: 658 (1973).

8. Fichman, M. P., Littenburg, G., Brooker, G., and Horton, R.: Effect of prostaglandin A. on renal and adrenal function in man. Circ. Res., 31 (Suppl. 11 ): 19 (1972).

9. Fichman, M. P., Telfer, N., Zea, P., Speckart, P., Golub, M., and Rode, R.: Role of prostaglandins in the pathogenesis of Bartter's syndrome. Am. J. Med., 60: 785 (1976)

10. Gall, G., Vaitukaitis, J., Haddow, J. E., and Klein, R.: Erythrocyte Na flux in a patient with Bartter's syndrome. J. Clin. Endocrinol., 32: 562 (1971).

11. Gardner, J. D.. Simopoulos. A. P., Lapey, A., and Shibolet, S.: Altered membrane sodium transport in Bartter's syndrome. J. Clin. Invest., 51: 1565 (1972).

12. Gill, J. R., Jr., and Bartter, F. C.: Evidence for a prostaglandin-independent defect in chloride reabsorption in the loop of Henle as a proximal cause of Bartter's syndrome. Am. J. Med., 65: 766 (1978).

13. Gill, J. R. Jr., Frolich, J. C., Bowden, R. E., Taylor, A. A., Keiser, H. R., Seyberth, H. W., Oates, J. A., and Bartter, F. C.: Bartter's syndrome: a disorder characterized by high urinary prostaglandins and a dependence of hypereninemia on prostaglandin synthesis. Am. J. Med., 61: 43 (1976).

14. Hoffman, J. F.: The red cell membrane and the transport of sodium and potassium. Am. J. Med., 41: 666 (1966)

15. Oliver, J. F., Delaney, V. B., and Bourke, E.: Increased erythrocyte sodium permeability in patients with Bartter's syndrome. Mineral Electrolyte Metab., l: 225 (1978).

16. Vaisrub, S.: Bartter's syndrome-limelight on prostaglandins. J. Am. Med. Assoc., 239: 137 (1978).

17. Werning, C., Vetter, W., Weidmann, P., Schweikert, V., Stiel, D., and Siegenthaler, W.: Effect of prostaglandin $E^{1}$ on renin in the dog. Am. J. Physiol. 220: 852 (1971).

18. The use of human volunteers reported in this paper was reviewed by an ethics committee before the study. Informed consent was received from the parents of the children involved.

19. The authors would like to thank Dr. Andrew Gonda and Dr. E. McGarry for making available some of the patients used in this study. The expert technical assistance of Florence McGrail was much appreciated and is duly acknowledged.

20. Requests for reprints should be addressed to: Dr. C. H. Cole, Nephrology Division, Department of Medicine, Royal Victoria Hospital, 687 Pine Ave. West, Montreal, Quebec, Canada, H3A 1 Al.

21. The research was funded partially by a grant from the Kidney Foundation of Canada.

22. Received for publication June 3, 1980

23. Accepted for publication November 3, 1980. 